\title{
Social Representations of Community Infection by Nurses of the Family Health Strategy
}

\author{
Lorena Karen de Morais Moura1, Carmen Viana Ramos², Maria Eliete Batista Moura3, \\ Andreia Rodrigues Moura da Costa Valle ${ }^{3}$, Luana Kelle Batista Moura ${ }^{4}$
}

\section{Abstract}

Background: Community infection that is detected or incubating on admission act, since not related to a previous admission in the same hospital. These infections constitute a public health problem by the risk that people are exposed in the community. The evaluation of the risk of infection is a complex process involving clinical, psychosocial, and environmental data.

Aim: Apprehend the social representations of community infection by nurses of the Family Health Strategy.

Methods: Exploratory qualitative study, conducted from February to March of 2016 in 18 basic health units of the Family Health Strategy (FHS), the Northern Regional Directorate, the city of Teresina, Piauí, Brazil, with 23 nurses. Data were collected through semi-structured interview, processed by software IRAMUTEQ and analyzed by descending hierarchical classification.

Results: The results were presented in two axes: Axis 1: The nurse in the prevention of infection in the Community Health Strategy, with the classes: Class 3: Measures to prevent infection Community; Class 4: Health education for the prevention of community infection; Class 5: Nurse Interventions for preventing infection Community; Axis 2: Extrinsic factors and social determinants related to community infection, with the classes: Class 2: The concept of community infection; Class 1: Types of community-acquired infections; Class 6: Risk factors for community-acquired infection.

Conclusion: The knowledge developed and shared by the nurses of the Family Health Strategy on Community infection, rooted in the
1 Nurse, Master. Professional Masters in Family Health, UNINOVAFAPI. Teresina, Piauí, Brasil.

2 Nutritionist. Doctor. Professional Masters in Family Health, UNINOVAFAPI. Teresina, Piauí, Brasil.

3 Nurse. Doctor. Nursing Post-Graduate Program. Universidade Federal do Piauí, UFPI. Teresina, Piauí, Brasil.

4 Dentist surgeon. Doctor. Professional Masters in Family Health, UNINOVAFAPI. Teresina, Piauí, Brasil.

Contact information:

Lorena Karen de Morais Moura.

Address: Rua Miosótis, 205, Jóquei, Teresina-Piauí. 64.048-130.

Tel: (86) 99980-0504.

झ lorennakaren@yahoo.com.br 
course of their professional practice, shows that the concept of community infection was not well built by professionals, referring only to unrelated infections to hospital.

\section{Keywords}

Social; Psychology; Community-Acquired Infection; Nursing.

\section{Introduction}

Infections Related to Health Care (IRHC) have represented over the centuries a major challenge for humanity. The fear on that issue has been strengthened in recent decades, resulting in highlight the role of health professionals, through preventive measures and the quality of care provided to the user.

The World Health Organization points out that throughout history, various infectious diseases such as bubonic plague, smallpox, typhus epidemic, Spanish flu, Asian flu, Hong Kong flu, avian flu, Severe Acute Respiratory Syndrome - SARS, influenza A H1N1 and multidrug-resistant bacteria, ravage the world and cause serious repercussions pandemic decimating much of the world's population [1].

The Ministry of Health of Brazil, through the Ministerial Directive 2616 of 1998 defined the Community Infection (IC) as: the infection detected in the act of the patient's admission, since not related to previous admission to hospital [2].

Primary Health Care is the main gateway to the National Health System, serving as a foundation for the structure of local health systems. Is a way to meet the health needs of the population by region and systematically integrating preventive and curative actions. Currently, the main PHC strategy in Brazil is the Family Health, aiming to expand of a particular population coverage and care reorganization, introduces the territorial processes and health responsibilities of health teams, composed mainly of general practitioner, nurses, nursing technicians and community health workers [3].

The Family Health Strategy (ESF) is the main strategy of Primary Health in the prevention of commu- nity infection, has supported better working practices in health promotion community through health education, community infections are acquired in the home environment or community [4].

In everyday practice must be implemented in health education activities so there is risk prevention and health problems, health promotion based on perceptions, features, adversities and limitations involving the population, since such measures can directly affect people's lifestyle by interfering in their consumption of goods and services.

A coresponsibility on the part of users regarding prevention of community-acquired infections is necessary, because these are acquired due to poor hygiene, bad care handling food and lack of care for household waste, among others. Thus, the nursing professional has a strategic role in the formation of a qualified assistance; in critical and creative dialogue with the reality of patients; the intervention capacity of the results in society, thus contributing to the formation of public policy.

The Social Representation Theory (SRT) is a way of thinking and interpret reality, a form of knowledge developed by individuals and groups to secure their positions in relation to situations, events, objects and concepts that affect them [5]. In this perspective, investigate the community infection as psychosocial phenomenon, subsidized by the Social Representation Theory, it is important to know subjective aspects that influence the behaviors and attitudes of nurses of the Family Health Strategy.

The social character of TRS contributes to the process of formation of conduct and guidance of social communications. Thus, social representations are equivalent to a set of principles built interacti- 
vely and shared by different groups, through them, understand and transform their reality [6].

The Theory of Social Representations should be analyzed for a better understanding of society, seeking to know how nurses take positions regarding the issue of community infection, in order to improve the effectiveness of their actions. Studies seeking to know the social representation about the community infection nurses are relevant, considering that the infection rates have been significantly reduced with the implementation of infection prevention measures. In this sense, it is important to adopt security measures for the care provided to patients, preventing or reducing the patient's risk to get an infection.

Articulate the Theory of Social Representation with a social problem, it is a challenging and complex proposal, demanding the investigation of social phenomena from the representation of these subjects, and how they communicate and interact socially [5].

Based on the Theory of Social Representations, one seeks to understand within a given group the development of representations of community infection and how these groups to prepare and transmit, seeking ways to prevent.

Thus, community infection, as a complex phenomenon, should be considered the influences of sociocultural nature. With this problem, the study aims to apprehend the social representations of community infection by nurses of the Family Health Strategy.

\section{Method}

This is a qualitative approach to exploratory research carried out in the period February-March 2016 in 18 basic health units of the Family Health Strategy - ESF, the Northern Regional Directorate of the city of Teresina, Piauí, Brazil, as a region of the city that has a high population density, poor sanitation and concentrate more nurses.
The study included 23 nurses working in the FHS, working for at least two years and have a institutional affiliation. Among the exclusion criteria it is emphasized: be away or on permit.

Data were collected in a closed room, by the researcher through a semi-structured interview guide applied to research participants, using audio equipment (.mp4) for recording speeches, with an average of 25 minutes per interview.

The data were processed using software IRaMuTeQ (R Interface pour les Analyses Multidimensionnelles of Textes et Questionnaires) [7]. Use of the Software has been increasing qualitative approach studies, particularly for allowing learn social construct of the subjects under study [8-11].

The data analysis was based on the method of descending hierarchical classification [7]. The corpus was formed by the set of texts to be analyzed, fragmented by software in text segments. During the preparation of the corpus were made readings, corrections and decodes of the fixed variables.

The field research followed the parameters established by Decree 466/12 of the National Health Council (CNS), which deals with ethical guidelines for research involving human subjects. The participants were informed about the real objectives of the study and the confidentiality of their responses in order to avoid future constraints.

The risks of the research were minimal, as embarrassment at the time of interview. To minimize this risk the researchers conducted interviews in private rooms, where they were not exposed, and were also clarified the goals and benefits of the research.

\section{Results and Discusions}

The IRaMuTeQ recognized separation of Corpus in 95 elementary units of text from 112 segments of text. 3901 occurrences were recorded, with use of $84.82 \%$ of the total corpus. The ranked segments were divided into 06 classes, with the occurrence percentage and $\mathrm{X}^{2}$ value higher classes. 


\begin{tabular}{|c|c|c|c|c|c|c|c|c|c|c|c|}
\hline \multicolumn{12}{|c|}{ Social representations of community infection prepared for nurses } \\
\hline \multicolumn{6}{|c|}{ The nurse in the prevention of infection in the Community Family Health Strategy } & \multicolumn{6}{|c|}{ Extrinsic factors and social determinants related to community infection } \\
\hline & 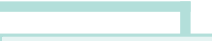 & & & & \multirow{2}{*}{\multicolumn{2}{|c|}{ Class 2}} & & & & \\
\hline \multicolumn{2}{|c|}{ Class 3} & \multicolumn{2}{|c|}{ Class 4} & \multicolumn{2}{|c|}{ Class 5} & & & \multicolumn{2}{|l|}{ Class 1} & \multicolumn{2}{|c|}{ Class 6} \\
\hline \multicolumn{2}{|c|}{16 UCE (16.84\%) } & \multicolumn{2}{|c|}{19 UCE $(20.0 \%)$} & \multicolumn{2}{|c|}{12 UCE (12.6\%) } & \multicolumn{2}{|l|}{17 UCE $(17.89 \%$} & \multicolumn{2}{|c|}{18 UCE (18.95\%) } & \multicolumn{2}{|c|}{13 UCE (13.68\%) } \\
\hline \multicolumn{2}{|c|}{$\begin{array}{l}\text { Measures for the } \\
\text { prevention of community- } \\
\text { acquired infections }\end{array}$} & \multicolumn{2}{|c|}{$\begin{array}{l}\text { Health Education for the } \\
\text { prevention of community- } \\
\text { acquired infections }\end{array}$} & \multicolumn{2}{|c|}{$\begin{array}{l}\text { Nurse's role in the } \\
\text { prevention of community- } \\
\text { acquired infections }\end{array}$} & \multicolumn{2}{|c|}{$\begin{array}{l}\text { The concept of } \\
\text { community infection }\end{array}$} & \multicolumn{2}{|c|}{$\begin{array}{l}\text { Types of Community } \\
\text { Infections }\end{array}$} & \multicolumn{2}{|c|}{$\begin{array}{l}\text { Risk factors for } \\
\text { community-acquired }\end{array}$} \\
\hline Word & $x^{2}$ & Word & $x^{2}$ & Word & $x^{2}$ & Word & $x^{2}$ & Word & $x^{2}$ & Word & $x^{2}$ \\
\hline Equipment & 43.1 & When & 34.9 & Nursing & 52.2 & Hospital & 45.1 & Virus infection & 17.8 & Sanitation & 55.1 \\
\hline Protection & 37.3 & Hands & 22.3 & Team & 29.0 & No & 29.1 & Exist & 13.2 & Basic & 48.8 \\
\hline Individual & 27.7 & Attend & 21.1 & Consultation & 29.0 & Comunity & 25.2 & Just & 13.2 & Question & 19.6 \\
\hline Use & 19.4 & Washing & 19.4 & Search & 28.8 & Acquire & 23.6 & Problem & 12.8 & Increase & 15.2 \\
\hline Cleaning & 15.3 & Orientation & 11.8 & Technique & 16.9 & Comunity & 15.9 & Care & 12.4 & Social & 7.3 \\
\hline Material & 15.0 & Realize & 8.7 & Educational & 10.7 & Surgery & 14.2 & Know & 5.7 & Conditions & 7.3 \\
\hline Thus & 13.0 & Always & 7.8 & Informations & 8.2 & Hospitalization & 13.8 & Hospital & 4.6 & Health & 7.2 \\
\hline Here & 11.3 & School & 7.8 & Visit & 8.2 & Understand & 13.8 & Pneumonia & 4.5 & Represent & 4.6 \\
\hline Glove & 10.6 & Lower & 7.8 & Importance & 8.2 & Relation & 11.3 & Example & 4.5 & Garbage & 4.6 \\
\hline Change & 10.0 & Lecture & 7.8 & Accomplish & 8.2 & Mean & 10.3 & Beside & 4.5 & Education & 4.6 \\
\hline Mask & 10.0 & Avoid & 7.8 & Necessary & 8.1 & Infection & 8.3 & Breathing & 4.5 & Comunity & 2.4 \\
\hline
\end{tabular}


Through Hierarchical Classification Descending were made possible the identification and analysis of textual domains other than the interpretation of the meanings, naming them with their meaning in classes as shown in Figure 1.

The corpus analyzed as a whole contained elements that address the knowledge and practice of nurses related to community infection. Initially, the corpus suffered a partition into two axes. Each axis originated three classes of consecutive subdivisions. The subdivision of Class 5 Class generated two (3 and 4), while the subdivision of the class 6 generated two classes (1 and 2).

\section{Class 3: Prevention Measures of Community Infections}

The main measures for the prevention of community-acquired infections extracted from the statements of interviewees recalled the use of personal protective equipment, proper hand hygiene and care related to the home environment. Understanding how nurses represent such measures can create subsidies for the development of strategies to promote a better practice. The representations of the study participants about the preventive measures were linked the main preventive measures used in the hospital environment.

The use of personal protective equipment when handling the patient before and after.

Suj. 11.

Use of personal protective equipment, guidance of the forms of patient hygiene, change of clothes, proper care for home use proper cleaning of environments

Suj. 13.

For the prevention of community infection it is necessary that the population know this kind of injury, allowing changes in their behavior to promote their health. The prevention, control and treatment of communicable diseases competing health profes- sionals, each with his knowledge and ability, making to occur changes in the epidemiological profile of the population. Therefore, the nursing interventions to exercise collective actions in the health-disease process seeks to improve the population's quality of life in its territory in question.

There is much work to be done to control and prevent community-acquired infections, surveillance and monitoring activities are just starting, social and environmental conditions such as poor sanitation, conditions of inadequate housing and incorrect practice of hand hygiene, are related to development infection [12].

Some European countries have started national campaigns to improve significantly reducing the risk of community-acquired infections, particularly infections related to multidrug-resistant bacteria, requiring cooperation between health facilities and public health authorities for quality management, promoting patient safety and health education. Generally, the emergence of community acquired infections are associated with interactions between the environment and humans and animals [13].

Hand hygiene is one of the most important actions in control for prevention of infections related to health care, control measures to reduce the rate of infections should be appropriate to the reality of each community, it is necessary that the population effectively participate in the actions of health.

\section{Class 4: Health Education for the prevention of community-acquired infections}

The representations of this class have been linked to health education practices in the community that are developed by professionals of the Family Health Strategy in the Basic Health Unit. The contents apprehended this class demonstrated the concern of nurses in developing health education techniques with the community, through guidance and lectures, there is a concern on the part of these professionals in health promotion in your community. 
Handwashing, educational activities, when done to meet a patient should not go soon meet the other without first rubbing alcohol in the hands.

Suj. 04.

Lectures in the community and in schools, we do it often, mainly because we have many patients.

Suj. 09.

The educative health actions can not be performed in vertical manner, one must know the reality of the individual and the community, seeking to know their daily life, promoting individual responsibility and collective cooperation [14].

Health education is a fundamental tool to improve the population's quality of life, especially regarding the health issue, it is necessary involvement by children, parents and responsible for the activities to achieve their goals. It is also a search for community empowerment, promoting the practices carried out in daily work, and seek to know and will evaluate the effectiveness of actions and direct other professionals in the implementation of the educational process [15].

When doing an educational approach to children is important that they understand the message, conveyed in a language accessible to age, parents and caregivers can take any doubts about optimal therapeutic approaches [14].

Must be created subsidies for the promotion of health of the population, preventing the onset of disease and its complications, education is the main tool for the control and prevention of infections. In a study of 26 nurses from 56 institutions was noticed that nurses act in the control of infection control, especially the hospital, through lifelong learning, group studies, academic guidelines in several areas, guidance and patient education. The professional nursing was one of those responsible for influencing the behavior of other health professionals, believe that education is the way to achieve change within the healthcare team and can reduce the risk of infection [14].
In everyday practice education actions should be implemented in health so there is risk prevention and health problems, health promotion based on perceptions, features, adversities and limitations involving the population, since such measures can directly affect people's lifestyle interfering including consumer goods and services. Therefore, it is necessary to implement educational measures and dissemination of what is what and how to treat community-acquired infections, because there is still a difficulty for professionals in identifying them.

\section{Classe 5: Nurse's role in the prevention of community acquired infections}

The contents apprehended this class showed the role of nurses in the prevention of community-acquired during nursing consultations in the Basic Health Unit and home visits in the community, highlighting its role in the prevention and control of community infections. The performance of professionals was favorable in all its evocations, professionals knew about the importance of their actions through a qualified assistance, reducing the risk of community infection.

In the community where we work should happen individual educational measures during the nursing consultation.

Suj. 15.

It is very important the work of the nursing staff, educating the community and caregivers, care needed to prevent infections.

Suj. 20.

The nurse has supported better working practices in community health promotion, has a strategic role in the formation of a qualified assistance; in critical and creative dialogue with the reality of patients; the intervention capacity of the results in society, thus contributing to the formation of public policy, understand the reality of the assisted community, recognize their difficulties and their needs. 
It can be said that the nurse in the Family Health Strategy is a "health provider". The consensus among professionals that primary health care is complex and requires a wide intervention in various aspects so that we can have a positive effect on the population's quality of life, requiring thus a set of knowledge so you can take the form of efficient practice, effective and resolute. One can even say that it is set as the first contact in the care network within the health system and is characterized mainly by the continuity and comprehensiveness of care, and the coordination of assistance within the system itself, the family-centered care, guidance and community participation and cultural competence of professionals [13-15].

Before their practices in the FHS the nurse brings with it desires, ambitions and expectations, seeking to improve and grow within the activities taht they develops with the community, create an integration environment with the community and the work environment itself, recognizing its varied and broader needs, will have a positive impact on production at all levels. Therefore, the nursing work near the community is fundamental to the health of people.

\section{Class 2: The concept of community infection}

From the replies given by nurses was evident that there is need for better conceptualization of criteria by parts of professionals, they still represent the community infection as not related to hospital infections, not associating the household factors (individual and collective) and peridomestic. In this class, the nurses showed a difficulty in conceptualizing, as well as associated risk factors for acquisition of the Community infection. Thus, it is possible to understand the psychosocial aspects present in the positions, the evocations of these professionals as they determine in the prevention and control of it, as the understanding of the concept helps to guide professional practice, building concepts related to the social phenomenon of the study.
Are infections acquired in the community even if they are not visible, are not related to the hospital they must to be related to community.

Suj. 08.

Well what I understand about community infection are those acquired in the community itself, the place where they live or that is in incubation and has no relation to the hospital.

Suj. 21.

In Brazil, the concept of community and hospital infection was approached by Decree 2616 of 1998 and the implementation of the Hospital Infection Control Commission, for better control of those in hospital settings, but did not address standards for infection control Community. This Decree addresses the community infection as the one detected at the time of the patient's admission to hospital or incubation provided no related hospitalization or an invasive procedure differs from hospital infection that manifests itself after admission to the hospital and its procedures [1].

To defer the Community infection hospital infection from diagnostic criteria, it is necessary sampling at the time of patient admission or 48 hours after hospital admission, timely necessary for the organism to develop. Historically, infections are categorized in community and hospital, community infections are those identified in incubation in samples taken in the first 48 hours of admission, since not related to previous admission to hospital and infections identified in samples taken after 48 hospitalization or after discharge are hospital infections [16].

\section{Class 1: Types of Community Infections}

In this class it is clear that nurses has knowledge of what types of community infections exist within their social reality, knowledge generated in their day-to-day, realize that it is a public health problem, these representations can interfere with the approa- 
ches adopted by them in relation to the represented object (community-acquired infections). However, it is necessary that these conducts are based through a praxis that the construction of this knowledge is based on joint discussions between the nurses and the population involved, that so this population lives, seeking its health promotion.

It sought in this class the understanding of social representations formed by nurses related to the types of community-acquired infections as a way to bring the practices developed by them. The relationships established between professional practices and representations are complex because they are formed from three elements: understanding the professional about the object of his practice, the context experienced by them and the population served.

There is no exact way to prevent infections, we are all susceptible to contracting.

Suj. 18.

Taking care of pneumonias, urinary tract infections take care of not to have problems, not aggravate the case as we know infection is a serious matter.

Suj. 02.

Guide as to care whether they are viral infections, these flus are examples of community infection.

Suj. 21.

I just remember tuberculosis, leprosy and also respiratory infections, such as pneumonia.

Suj. 07.

The most detected community infections are respiratory infections, urinary tract infections, skin infections and parasitic diseases, with children and the elderly are the groups most affected due to the weakness of their immune system, a fact made worse if there is a chronic disease [17].

Over time, there was a greater concern with issues related to community infection and control of cross-infection, since it is related to several factors, such as social, environmental and personal.

\section{Class 6: Risk factors for community- acquired infection}

In this class it was sought to show that risk factors involved and social determinants for the acquisition of community infection. In their speech, the most mentioned words back the socioeconomic conditions involved and the difficulties of establishing control measures appropriate to the reality of that population. The words showed that social cognitive content present in the testimonies of the nurses showed a search of these professionals in reducing Community infection, sharing knowledge socially, but have restrictions during their interventions due to existing social dichotomies in communities.

Poor housing and sanitation, are related to the development of infection.

Suj. 12

he issue is that people underestimated the vaccination they think they already have immunity, so they no longer worry about it, our role is to recover the issue of their health promotion.

Suj. 22.

Brazil is a large and complex country that is going through economic, social and environmental change, through significant improvements in the health status of the population and life expectancy, which can be attributed in large part by social determinants of health progress and the implementation of a comprehensive national health system with strong social participation. Many challenges remain, however, socio-economic and regional disparities are still unacceptably large. New health problems arise as a result of social and environmental urbanization, continued engagement of the Brazilian society as a whole to ensure the right to health for all Brazilian people is necessary [18]. 
Socioeconomic difficulties limit preventive practices such as lack of toilets, running water at home, difficulty in purchasing water filters, among others [8]. It is necessary that several factors are linked to the occurrence of a decrease in risk factors for community-acquired infections, such as adequate sanitation, adequate housing, improvement in personal hygiene and safety precautions.

It is important to promote a care health in their own home environment properly, including educational and health care activities such guidelines relate to sanitation, use of appropriate medications, health-care, breastfeeding, weight control, therefore it is a way of home care [19].

It is necessary to know the profile of community infections making constant periodic evaluations because it may cause changes in the behavior of microorganisms, mainly due to the use of antibiotics indiscriminately and may compromise the effectiveness of drugs that are important in the treatment of infections. There are differences between the guidelines that are published and clinical practice related to the use of antimicrobials, as there is an incomplete application of current literature recommendations, leading to the need to develop educational protocols and evidence-based strategies [20].

In a study by Kenneley [12] evidenced an increase in the incidence of community-acquired infections caused by multidrug-resistant bacteria. The implementation of prevention and infection control strategies, including education and training of professionals is necessary, proper hand hygiene, proper decontamination of surfaces, careful cleaning of the environment by interrupting the chain of transmission of these microorganisms.

One must draw the attention of healthcare professionals for appropriate assistance to the community, it is an innovative strategy, which includes the individual and their families, including social dimensions. This model of attention to humanized health is well away from iatrogenic risks belonging in the hospital setting.
Generally the infection has a high mortality rate, being directly or indirectly responsible for the increase in morbidity and mortality, thus raise costs for the patients themselves and their families. The environment and poor sanitary conditions in which the population lives may be related to the acquisition of some diseases.

Thus, the Theory of Social Representations used in research on the phenomenon of community infection possible to create concepts, explanations and statements from the daily life of nurses through communications between individuals and the shared knowledge and developed for them.

\section{Conclusion}

As we seek the representations of nurses on community infection in the Family Health Strategy, we find meanings, elaborated by different professionals, portraying their views on the issue within your reality. These representations were presented as sets of ideas developed by them as social subjects. The knowledge developed and shared by nurses of the Family Health Strategy on Community infection, rooted in the course of his professional practice, shows that the concept of community infection was not well built by professionals, referring only to infections not related to the hospital.

\section{References}

1. Organização Mundial da Saúde. Manual de classificação estatística internacional de doenças, lesões e causas de óbito; 9a Revisão, 1975. São Paulo, Centro da OMS para Classificação de Doenças em Português; 1978.v.1.

2. Ministério da Saúde (BR). Portaria 2.616, de 12 de maio de 1998. Dispõe sobre a prevenção e controle das infecções hospitalares: Diário Oficial da União, jul 1998. Available from: <http://portal. anvisa.gov.br/wps/wcm/connect/8c6cac8047457a6886d6d63f bc4c6735/PORTARIA+N\%C2\%B0+2.616\%2C+DE+12+DE+MAI $\underline{O}+\mathrm{DE}+1998 . p d f ? \mathrm{MOD}=\mathrm{AJPERES}>$. Acessed in: 09 de agosto de 2015. 
3. Matta GC, Morosini MVG. Atenção primária à saúde. Escola Politécnica de Saúde Joaquim Venâncio (Org.). Dicionário da Educação Profissional em Saúde. 2010; 1:23-8.

4. Alves $G G$, Aerts D. As práticas educativas em saúde e a Estratégia Saúde da Família. Ciênc. saúde coletiva. 2011;16(1):319-25.

5. Moscovici S. Representações Sociais-Introdução em Psicologia Social. 7th ed. São Paulo: Vozes, 2013.

6. Reigota M. Meio ambiente e representação social. 8th ed. São Paulo: Cortez, 2010

7. Camargo BV, Justo AM. IRAMUTEQ: um software gratuito para análise de dados textuais. Temas psicol. 2013;21(2):513-8.

8. Sousa AFL, Queiroz AAFLN, Oliveira LB, Valle ARMC, Moura MEB. Social representations of community-acquired infection by primary care professionals. Acta paul enferm. 2015; 28(5):4549.

9. Moura LKB, Marcaccini AM, Matos FTC, Sousa AFL, Nascimento GC, Moura MEB. J res fundam care online. Integrative review on oral câncer. 2014;6(5):164-175.

10. Moura LKB, Sousa AFL, Nascimento GC, Queiroz AAFLN, Sousa DM. Biosafety measures in dental procedures: an integrative review. J Nurs UFPE on line.2015; 9(10)1537-44

11. Sousa AFL, Queiroz AAFLN, Oliveira LB, Moura MEB, Batista OMA, Andrade D. Social representations of biosecurity in nursing: occupational health and preventive care. Rev Bras Enferm. 2016;69(5).

12. Kenneley IL. Infection control and the home care environment. Hom Health Care Manag Pract. 2010;22(3):195-201.

13. Gastmeie, P. Healthcare-associated versus community-acquired infections: A new challenge for science and society. International Journal of Medical Microbiology.2010;300(6):342 -5.

14. Barbosa MEM, Siqueira DC, Mantovani MF. Nosocomial infection control in Paraná: nurse's facilities and difficulties. Rev. SOBECC. 2012;17(3):50-9.

15. Valle ARMC, Andrade D, Sousa AFL, Carvalho PRM. Infection prevention and control in households: nursing challenges and implications. Acta paul enferm. 2016; 29(2):239-44.
16. Gradel,K.O, Nielsen, H.L, Schonheyder, H.C, Ejlertsen,T., Kristensen $B$, Nielsen $\mathrm{H}$. Increased short- and long-term risk of inflammatory bowel disease after salmonella or campylobacter gastroenteritis. Gastroenterology. 2009;137:495-501.

17. Falsey AR, Hennessey PA, Formica MA, Cox C, Walsh EE. Respiratory syncytial virus infection in elderly and high-risk adults. N Engl J Med. 2005 Apr 28;352(17):1749-59.

18. Victora CG, Barreto ML, Leal MC, Monteiro CA, Schmidt MI, Paim J, et al. Health conditions and health-policy innovations in Brazil: the way forward. 2011;377(9782): 2042-53.

19. Lacerda MR. Atenção à Saúde no Domicílio: modalidades que fundamentam sua prática. Rev Saúde Socied.2006;15(2):88-95.

20. Salluuh et al. Tratamento da pneumonia grave adquirida na comunidade no Brasil: análise secundária de um inquérito internacional. Rev Bras Ter Intensiva. 2015;27(1):57-61.
Publish in International Archives of Medicine

International Archives of Medicine is an open access journal publishing articles encompassing all aspects of medical science and clinical practice. IAM is considered a megajournal with independent sections on all areas of medicine. IAM is a really international journal with authors and board members from all around the world. The journal is widely indexed and classified Q2 in category Medicine. 